\title{
Comparison of Durability of Gaziantep Village Cookies Prepared With Chickpea Yeast and Dry Yeast by Using Sensory Evaluation Test
}

\author{
Fatma Yaliniz \\ Gaziantep University, Faculty of Art, Department of Gastronomy, \\ 27310, Gaziantep, Turkey \\ E-mail: albak@gantep.edu.tr \\ Orcid.org/0000-0002-2002-3037
}

\begin{abstract}
Gaziantep village cookies, which was patented as Geographical Indicated Product category by Turkish Patent Institute on 28.12.2017, is originally produced with chickpea yeast. However production steps of chickpea yeast are difficult and therefore many producers use dry yeast. In this study, the durability of chickpea and dry yeast-produced Gaziantep Village Cookies was compared by using sensory test. The same recipe was used in cookies prepared with dry and chickpeas yeast. Only yeast are different. Recipe was formed by interviewing with 10 women (over the 50 years old) born and bred in Gaziantep. The taste, color, odor and hardness of these cookies were evaluated sensitively for every 15 days during 2,5 months. Hedonic scale analysis was performed with semi-trained panelist. The results of the sensory tests were statistically evaluated by using the One-way ANOVA test in SPSS 15.0 (Version $2.0)$. It has been seen that time $(p>0.05)$ is not an important factor for taste, color, odor and hardness of cookies made with chickpea yeast. It has been observed that time $(\mathrm{p}>0.05)$ is not an important factor for taste and color of cookies made with dry yeast but time is an important factor for odor and hardness of these cookies $(\mathrm{p}<0.05)$
\end{abstract}

Keyword: Gaziantep, village, cookies, chickpea, dry, yeast.

DOI: $10.7176 /$ JSTR/6-10-03

\section{INTRODUCTION}

\section{Cuisine Culture of Gaziantep}

Gaziantep, which is one of the important stops of the historical Silk Road route, has hosted many different cultures for thousands of years and has created a unique culture by blending these cultures. The most ambitious area of Gaziantep culture enriched with the combination of differences is the food culture. In this success of Gaziantep, as well as the accumulation of the past, the generosity of the nature and the devotion of the people have a big share. Because the golden rule of Gaziantep cuisine: using local and quality materials. Gaziantep, one of the most important settlements of our country with its rich historical and geographical location, presents a unique cultural structure that makes colorful of the Turkish Kitchen Tradition with its variety of dishes. Throughout history, although the people who love the air, water and soil of this city have different languages, religions and ethnicities, they have a common taste and have been involved in the emergence of today's rich Gaziantep Culinary Culture. Gaziantep Cuisine is a universal richness that carries the traces of the civilizations that have reigned for centuries in this land. All the cooking techniques including grilling, frying pan, saute, roasting, cooker dishes, oven cooking techniques are used in Gaziantep cuisine (www.Gaziantepface.com)

Gaziantep cuisine, which has about 400 original food, is a meat-based kitchen. More sheep meat is consumed by these people lived in Gaziantep. The main feature of the this kitchen is that it contains many types of kebabs. On the other hand, it would be a great mistake to think that Gaziantep's food culture is only consisted of kebab. In fact, vegetables and fruits are widely used in the this kitchen; moreover, it has a culinary tradition in which spices and yogurt play a major role in food of Gaziantep. Foods are made with plenty of oil in a region-specific tradition, and oil is considered to be an important

19 | P a g e

www.iiste.org 
factor affecting the flavor of the dish. The quality of paste is also very important for kitchen of Gaziantep. Pomegranate syrup is widely used in recipes of meal. Bulgur is the most important ingredient of many dishes after meat. The dried vegetables such as eggplant, zucchini, pepper, and stuff made with this dried vegetables are important elements of Gaziantep Cuisine. Pastries, especially lahmacun, are also found in Gaziantep tables.

\section{Gaziantep Cuisine Culture and UNESCO}

The name of Gaziantep according to expresssion's Evliya Çelebi is Şehr-i Ayıntab-1 Cihan. In other words, it is the light and light of cities of the world. Gaziantep Culture, which has successfully preserved all its cultural identity with its history, geography, social structure, neighbors, cosmopolitan city climate, food culture, folklore, regional art elements, clothing styles from past to present and still preserves and is still being tried to transfer to future generations, has a special place in our country and in the world with its culinary culture. With this privilege, Gaziantep Cuisine was registered in the Gastronomy field in December 2015 by UNESCO (United Nations Educational, Scientific and Cultural Organization) with its hundreds of different products and cultures and included in the Creative City Network, which has only 17 cities in the world. It succeeded to be the 18th city. As the first city to achieve this success, it has passed into the hiştory of Turkish and world gastronomy.

\section{Gaziantep Village Cookies}

Arabic word "kahke", which means bracelet, is brought from the city of Aleppo in Syria in the early 1900 s by the masters of Antep and is known as a product made to make children love fasting during Ramadan. The number of cooky made in Gaziantep until 1950s does not exceed five or six. There are varieties such as oily cooky, bagel cooky, sesame cooky, Ramadan cooky, Aleppo cooky. Antep village cookies which is the subject of registration is a kind of sweet cooky. The most important characteristic of Antep village cookyi is that it is made with chickpea yeast. The chickpea used in terms of locality of the product is a type of chickpea, which is unique to Gaziantep, is the genus of Koçbaşı. Chickpea yeast causes Antep village cooky to become dispersible in the mouth and prolong its durability. In addition, the spices and shape used in this type of cookies are the distinguishing features. Antep village cooky is a special cooky made in Gaziantep, especially during Ramadan Holidays, which contains spices such as fennel, black seed, cinnamon and sesame. It is produced by passing special processes with chickpea yeast. It is a product that disperses in the mouth and maintains its freshness for 3-4 months. The most important factor in maintaining its freshness is that the fermentation process is different from other cookies. In this type of fermentation, chickpeas are divided into pieces and fermented, unlike sour yeast, which takes a shorter time and easier to make a pungent, sweet yeast is obtained (www.gastromanya.com)

\section{MATERIAL-METHOD}

\section{Preparation of Chickpea Yeast}

Required substances for 500 gr chickpea yeast: 100 gr chickpess, 140 gr flour (contain $\% 7$ protein), $250 \mathrm{ml}$ water and $5 \mathrm{gr}$ salt. Chickpeas are broken into several pieces for the yeast to be obtained. The shredded chickpeas are put into the glass jar which was previously shaken with boiling water. Sprinkle with flour and salt to gently shake and mix and let in air. Water is then added at $45-46^{\circ} \mathrm{C}$. Water is added up to $2.5-3.0 \mathrm{~cm}$ above the yeast mixture. The amount of water does not matter and only the yeast mixture should be covered well. The glass jar is closed so that it is not too tight and waited 24 hours. The ambient temperature during the fermentation period should be around $45-46^{\circ} \mathrm{C}$.

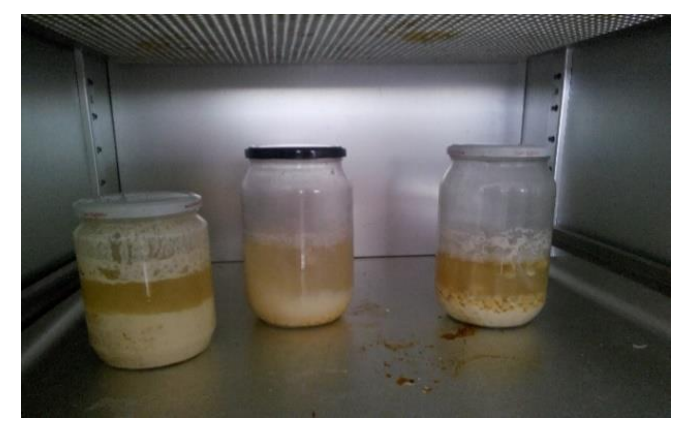

Figure 1 Fermented chickpeas yeast 
After this stage shown in Figure 1, the sediment part of the chickpeas will not be used. Only the above portion of the serum (aqueous portion) will be used for making the front chickpea yeast.

\section{Preparation of Front Chickpea Yeast}

Required materials for front chickpea yeast are $200 \mathrm{gr}$ flour (containing $\% 7$ protein), $200 \mathrm{ml}$ water and whole of the active yeast serum obtained. All of the above materials are mixed thoroughly. Then, the mixture is covered and air contact is stopped and it is waited for 24 hours. When air bubbles appear on the front yeast, it is ready for use.

In the Figure 2 given below, swelling caused by carbon dioxide output as a result of activation of anterior chickpea yeast which is allowed to ferment at $42^{\circ} \mathrm{C}$ for 24 hours is observed.
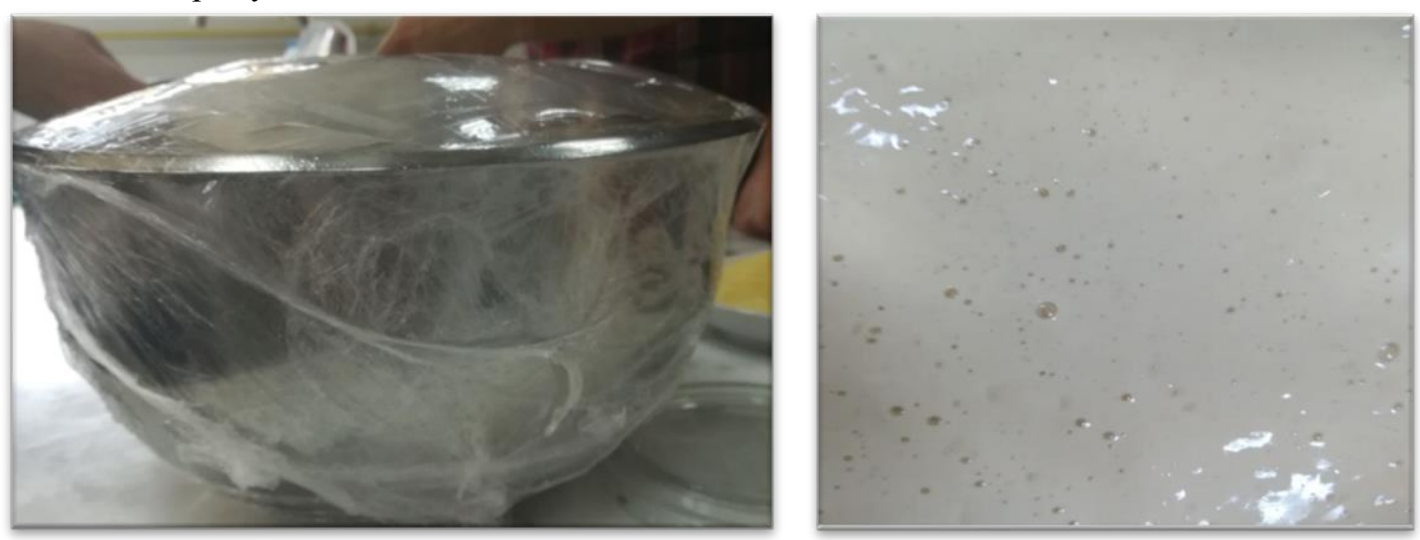

Figure 2 Front chickpea yeast

Shown in Figure 2, the air bubbles and carbon dioxide output on the yeast are clearly visible. After this stage, the front chickpea yeast is ready to use. Front chickpea yeast was added to the main dough.

\section{Preparation of Gaziantep Village Cookies with Chichkpea Yeast}

Required material for Gaziantep village cookies are $1000 \mathrm{gr}$ flour (containing \%7 protein), $200 \mathrm{gr}$ semolina, 350 gr grape molasses, 133 gr sugar, 187 gr olive oil, 250 gr butter, 375 gr yoğurt, 5 gr salt, $1 \mathrm{egg}, 60 \mathrm{gr}$ sesame, $40 \mathrm{gr}$ black seed, $10 \mathrm{gr}$ mahlep (family of rosaceae and fruit of wild cherry) and 10 gr mayana ( is the family of fennel).
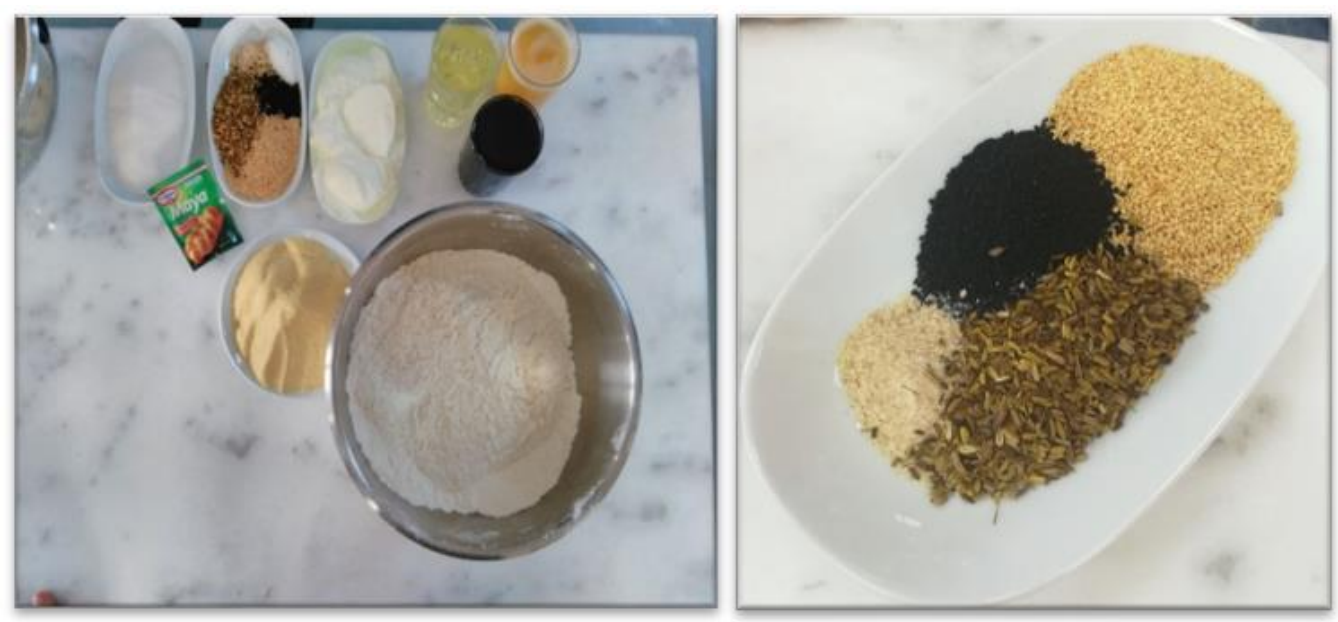

Figure 3 Required materials for Gaziantep village cooky with chickpea and instant yeast

Two cooky varieties were prepared from the above materials shown in Figure 3 using chickpea yeast first, then removing chickpea yeast from the recipe and using instant yeast instead. All measurement and process steps used are the same for the two type of cooky. During the preparation stage, the yeast was roasted and cooled to reveal its smell and aroma. The dry materials were sieved, butter melted and

21 | P a g e 
cooled. In the mixing bowl for dough, butter, sugar, molasses, eggs, and yogurt are added and mixed thoroughly. Then the spices are added and mixed. After consistency, about 200 grams of the front chickpea yeast is added to the mixture. Dry materials are added to the liquid materials in a controlled manner. When the dough begins to acquire a homogeneous structure, the dough is completed. For at least 2 hours the yeast is kept at room temperature with its mouth closed to activate. Chickpea leavened dough is ready to use.

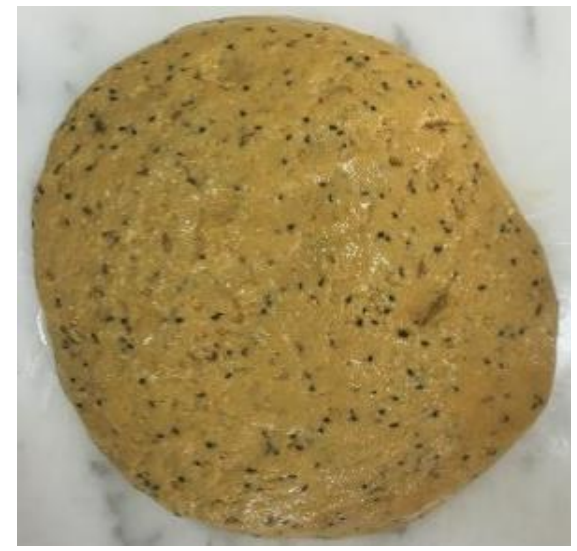

Figure 4 Dough of Gaziantep village cooky with chickpea yeast

\section{Preparation of Gaziantep Village Cookies with Instant Yeast}

In the mixing bowl, 10 grams of sugar, 20 grams of instant yeast and a little warm water are mixed and yeast is activated.
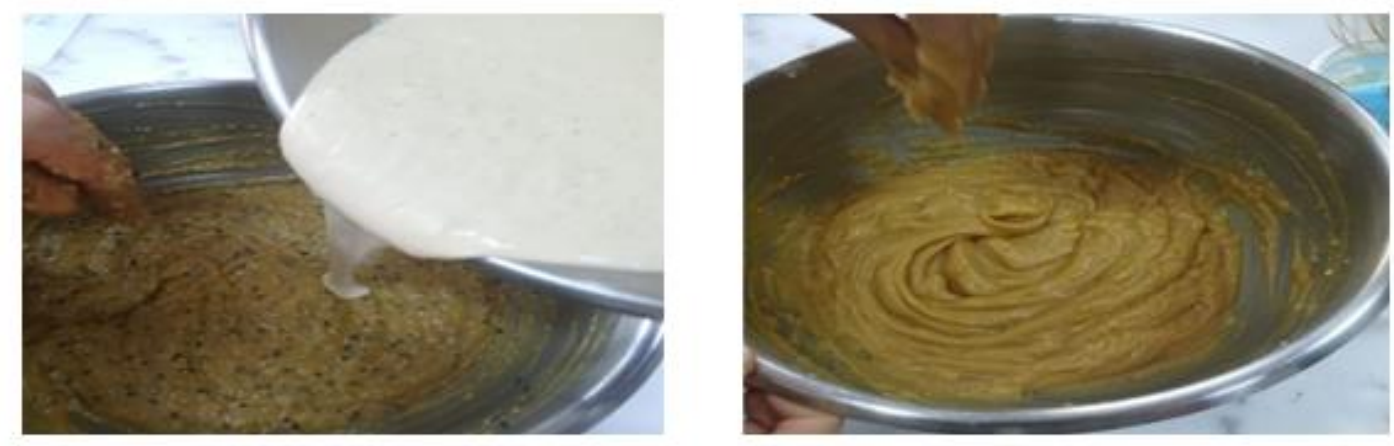

Figure 5 Preparation of Gaziantep village cooky with instant yeast

After the yeast starts to foam, butter, remaining sugar, molasses, eggs, and yogurt are mixed. Spices are then added. Dry materials are added to the liquid mixture in a controlled manner. The dough is completed when it starts to gain a homogeneous structure. For at least 2 hours the yeast is kept at room temperature with its mouth closed to activate. Instant leavened dough is ready to use.

\section{Shaping the Cooky Dough}

All fermented doughs are divided into $20 \mathrm{~g}$ pieces shown in Figure 6. Oil molasses mixture is applied on the doughs. The prepared doughs are rested at $42-45^{\circ} \mathrm{C}$ for 2 hours before they are put into the oven. 

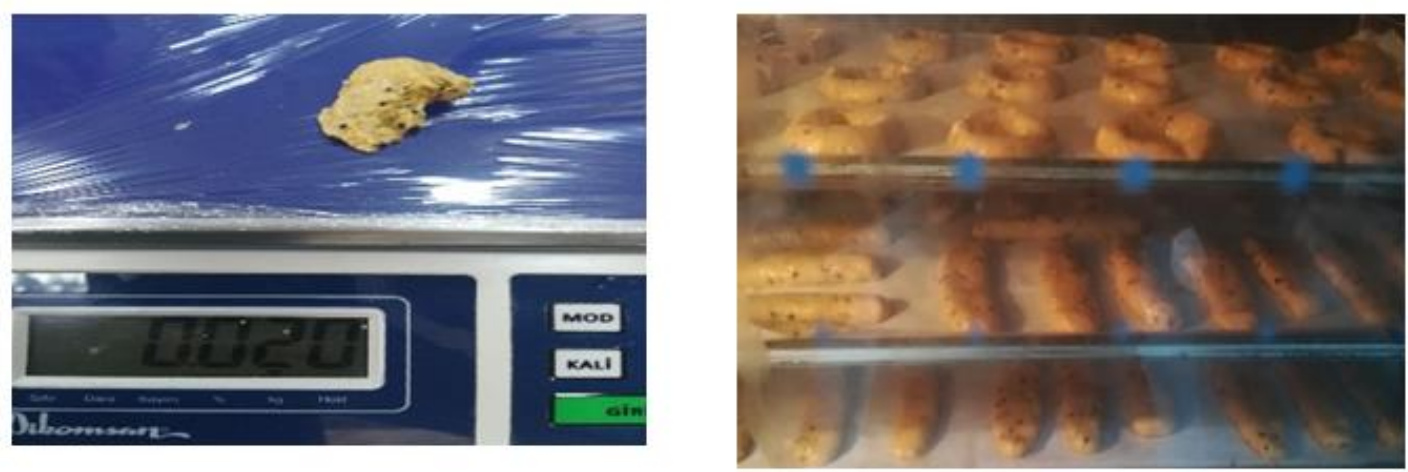

Figure 6: Weighing the cooky dough for giving shape.

The rested dough in trays was placed in an oven pre-heated to $180^{\circ} \mathrm{C}$. The cooking time is approximately 20-25 minutes. The top and bottom of the dough is cooked until lightly browned. When cookies are first come out of the oven, the cookies are very fragile shown in Figure 7. Therefore, the trays should not be emptied immediately and should be allowed to reach room temperature.
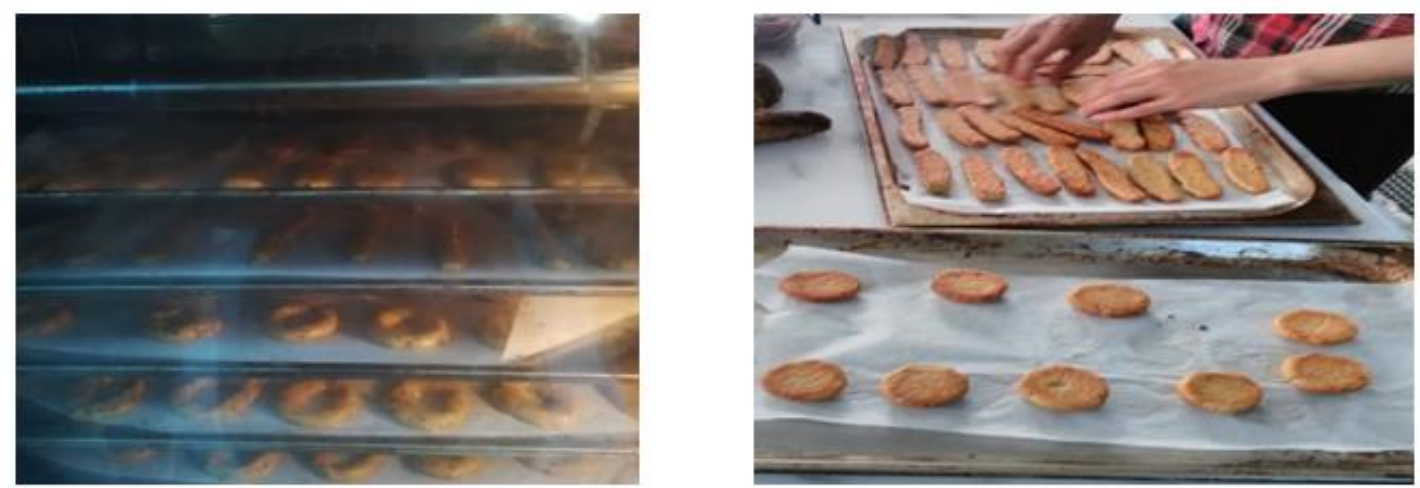

Figure 7 Cookies in the oven and cooked cookies.

\section{Storage the Cooked Cookies}

The product was stored at room temperature in sealed containers for preventing moisture absoprtion three months. They were stored in closed containers to prevent moisture absorption. No information is available whether it is closed or open. However, it is recommended for storage in closed containers for hygiene.

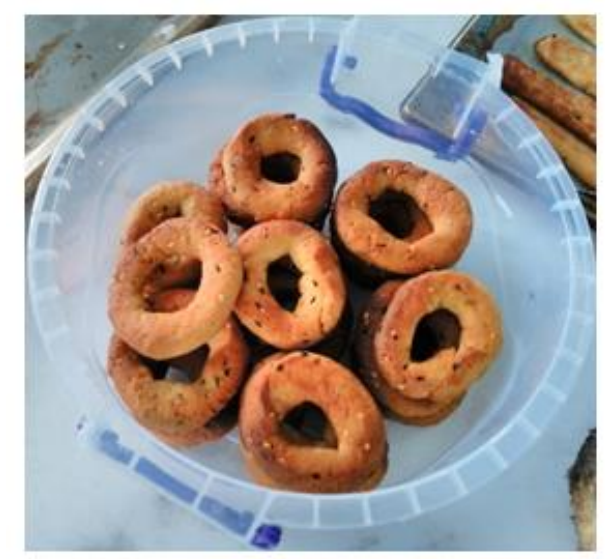

Figure 8: Storage of cookies in closed containers.

23 | P a g e 


\section{Sensory Analysis}

Sensory analysis was applied to reveal which yeast is more suitable for consumption, general acceptance of products and more durable in terms of shelf life by comparing the cookies prepared with chickpea yeast and instant yeast according to taste, texture, color, hardness criteria, general acceptance and shelf-life. Six sensory analyzes were performed over a 3-month period. 10 participants participated in each analysis. Individuals evaluated the products independently during testing. The products were evaluated by giving different codes and which code belongs to which product is not known by the panelist. 9-hedonic scale sensory evaluation was used for evaluation of general acceptance of products, determination of storage durability and shelf-life, and acceptance of taste, texture, color, hardness criteria. The analyzes were conducted with 10 semi-trained panelists. Before each analysis, the panelists were given about half an hour of training. The age range of the panelists was 25-35 years. Panel tests were performed between 11:00 a.m. and 11:30 a.m. at room temperature. Samples were given to panelists in the panel booth. Panelists were asked to evaluate the samples and mark the order of preference and the intensity of the sensory property (taste, color, smell and hardness) on the given scale shown in Table 1. Panalists evaluated each sample after rinsing with water and waiting for one minute. The results of sensory analysis were evaluated using variance analysis in SPSS program (15.0.0 Copyright (C) SPSS Inc. 2001).

Table 1. Hedonic scale for cookies.

\begin{tabular}{|l|l|l|l|}
\hline Liking Score & Panelist Hedonic Rating & Sample I & Sample II \\
\hline 9 & Like extremely & & \\
\hline 8 & Like very much & & \\
\hline 7 & Like moderately & & \\
\hline 6 & Like slightly & & \\
\hline 5 & Neither like nor dislike & & \\
\hline 4 & Dislike slightly & & \\
\hline 3 & Dislike moderately & & \\
\hline 2 & Dislike very much & & \\
\hline 1 & Dislike extremely & & \\
\hline
\end{tabular}

\section{RESULT AND DISCUSSION}

The aim of this study is to compare the taste, flavor, hardness, appearance and shelf life of the Gaziantep village cookies, which is a local product of Gaziantep cuizine, made with chickpea and instant yeast and to determine which one is better quality by using sensory analysis. The change of the quality parameters of both cookies was investigated with respect to time. The quality parameters of cookies were evaluated by using a sensory analysis every 15 days for three months and the results were statistically evaluated in SPPS(15.0.0 Copyright $@$ C SPSS Inc. 2001). The results of sensory analysis test were evaluated by one way ANOVA test in SPSS. Tukey test was used for paired multiple comparisons. When the statistical results were examined, it was found that time ( $p>0.05)$ was not an important parameter in taste, color, smell and hardness of cookies made with chickpea yeast.

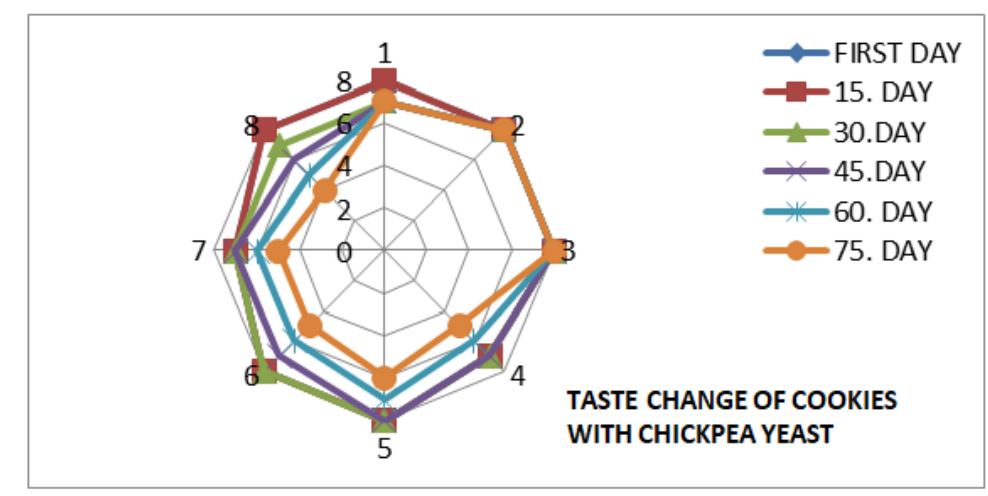




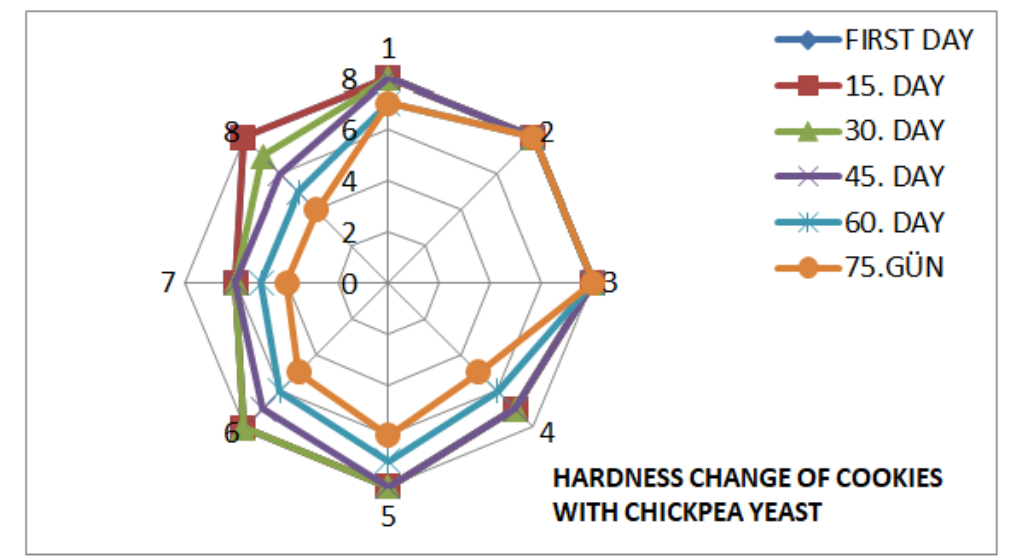

(b)

Figure 9 a-b Taste and hardness change of cookies with chickpea yeast with time.

When Figure 9 is examined, it is observed that decreases in hardness and taste parameters of cookies with chickpea yeast have started after the tenth week.

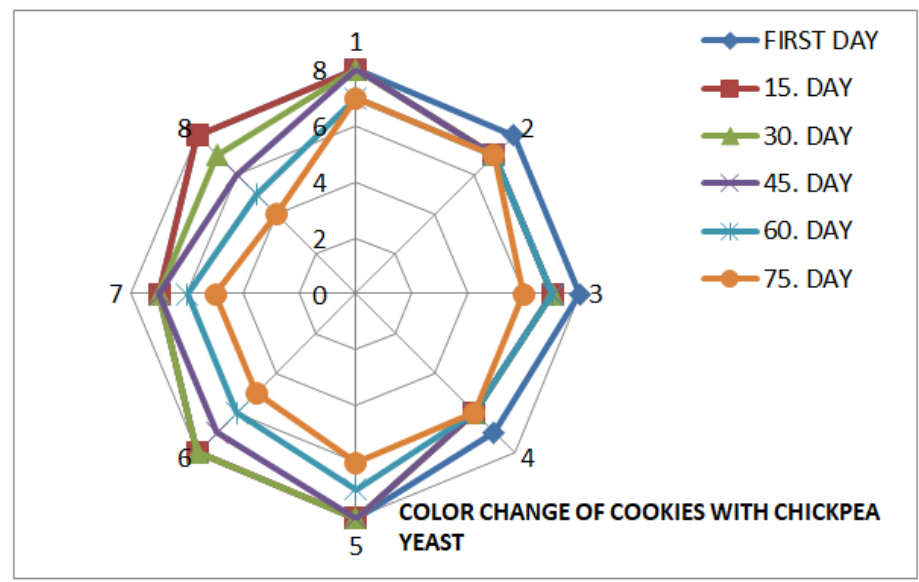

(a)

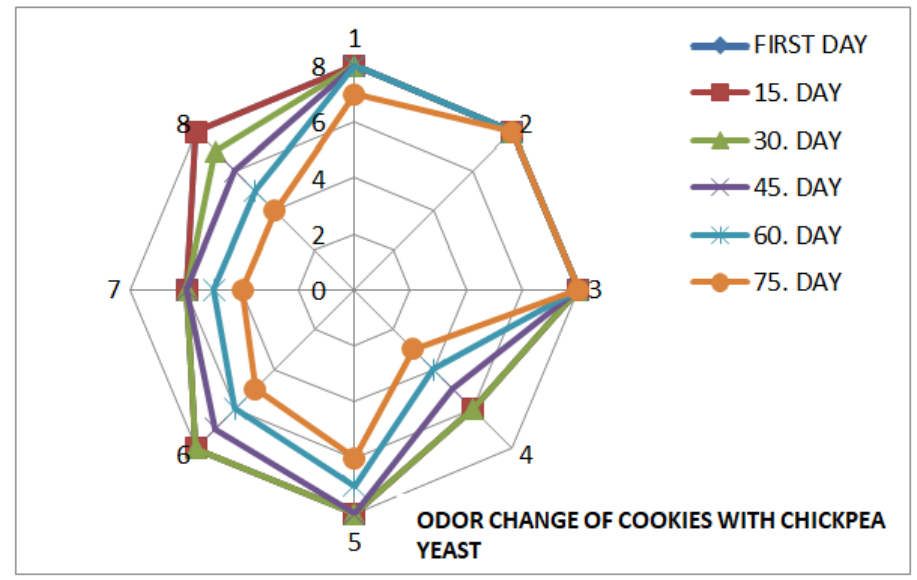

(b)

Figure 10 a-b Color and odor change of cookies with chickpea yeast with time. 
When Figure 10 is examined, it is observed that decreases in color and odor parameters of cookies with chickpea yeast have started after the tenth week. According to this study, cookies with chickpea yeast made without any preservatives can maintain freshness in taste, color, smell and hardness for about ten weeks at room temperature. This study was carried out in Gaziantep in spring. It was started to wait at room temperature in March and was terminated at the end of May. During the study period, the air temperature changed between $20-31^{\circ} \mathrm{C}$ in Gaziantep. The ambient temperature of the products waited was changed between 16-26 ${ }^{\circ} \mathrm{C}$. This product was made in Gaziantep especially in the Ramadan holiday and stored in the home environment. Therefore it was also adhered to the traditional storage conditions of this product during this study.

When the statistical results were examined, it was found that time $(p<0.05)$ was an important parameter in taste, smell and hardness of cookies made with instant yeast and was not important for color criteria ( $\mathrm{p}>0.05)$ of cookies with instant yeast shown in Figure 11.

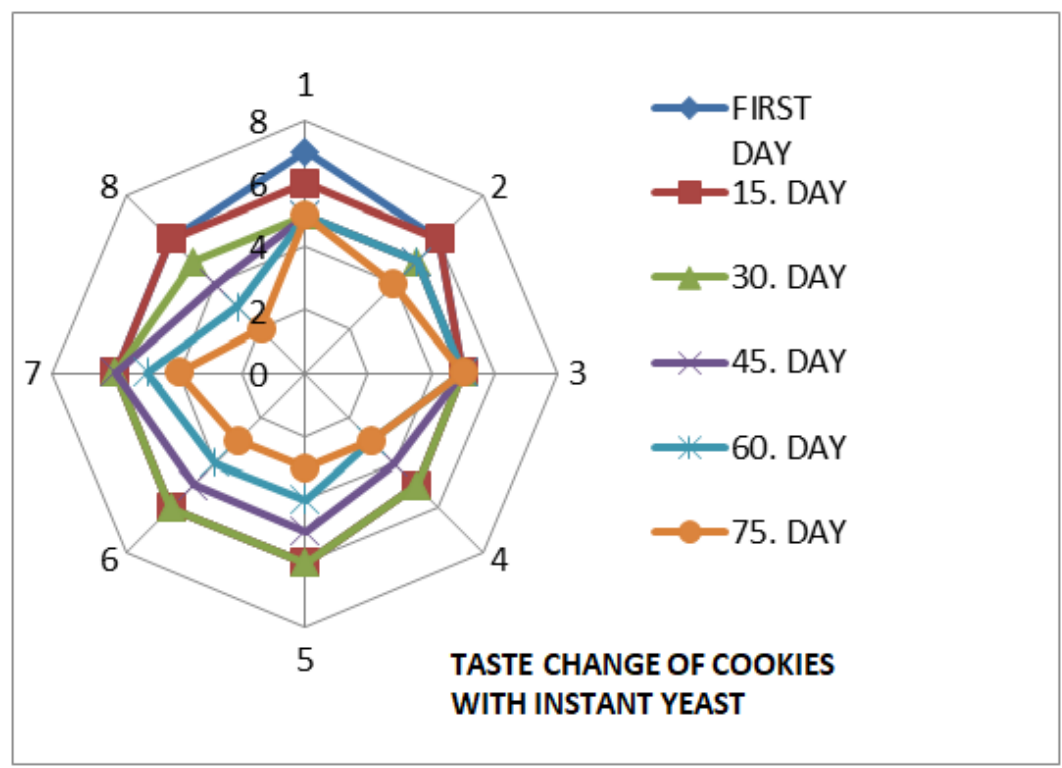

(a)

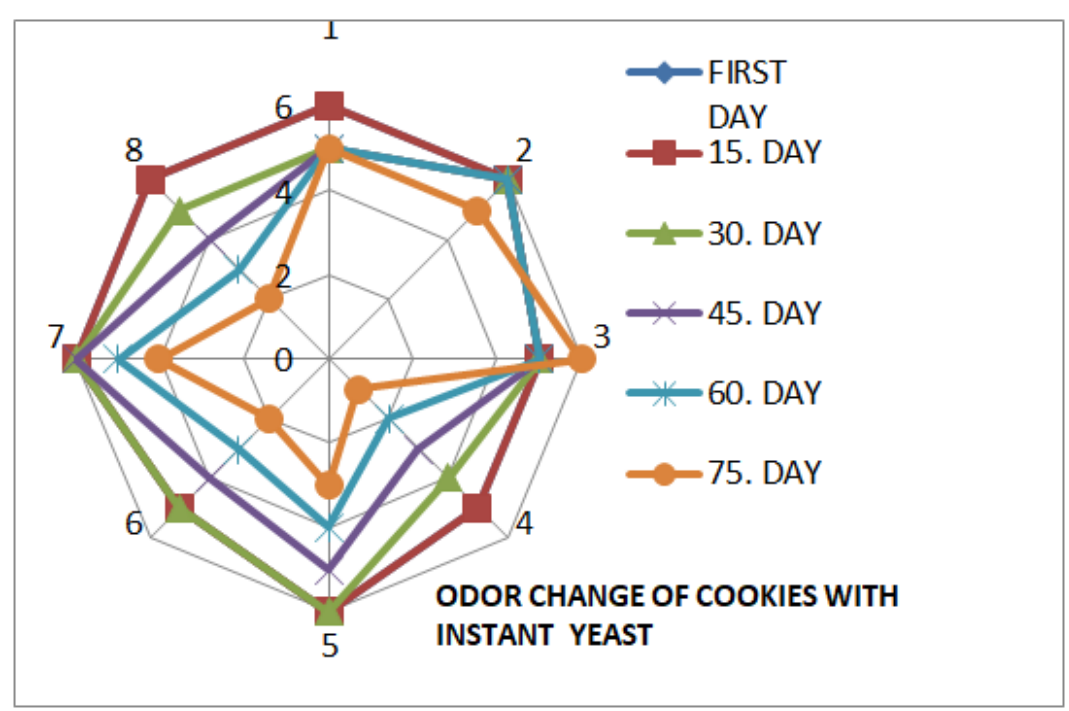

(b) 


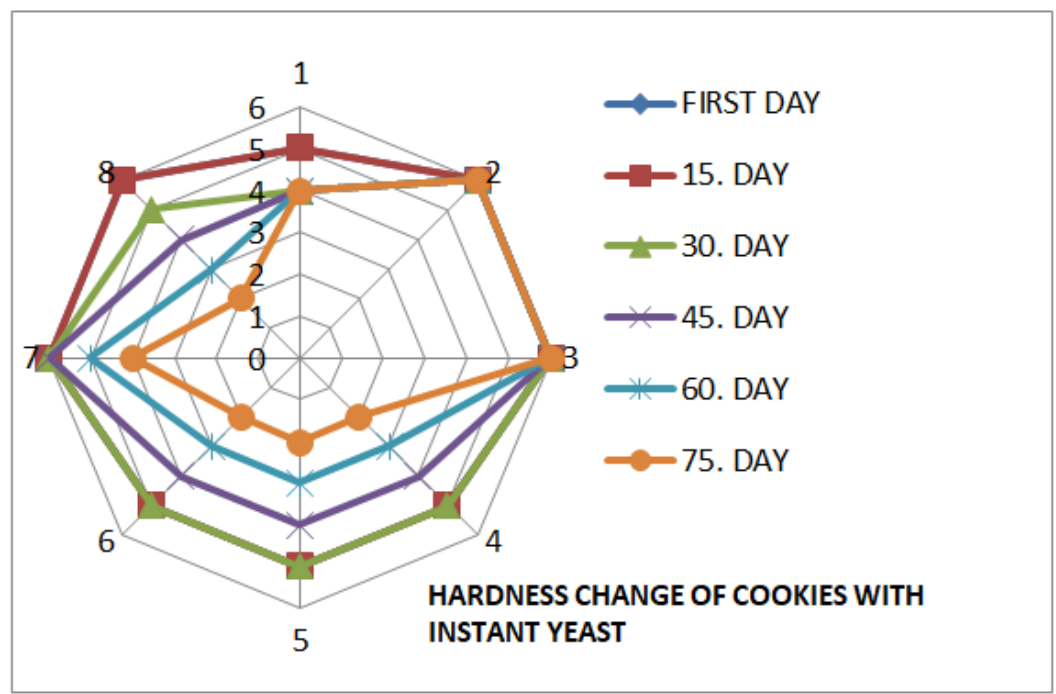

(c)

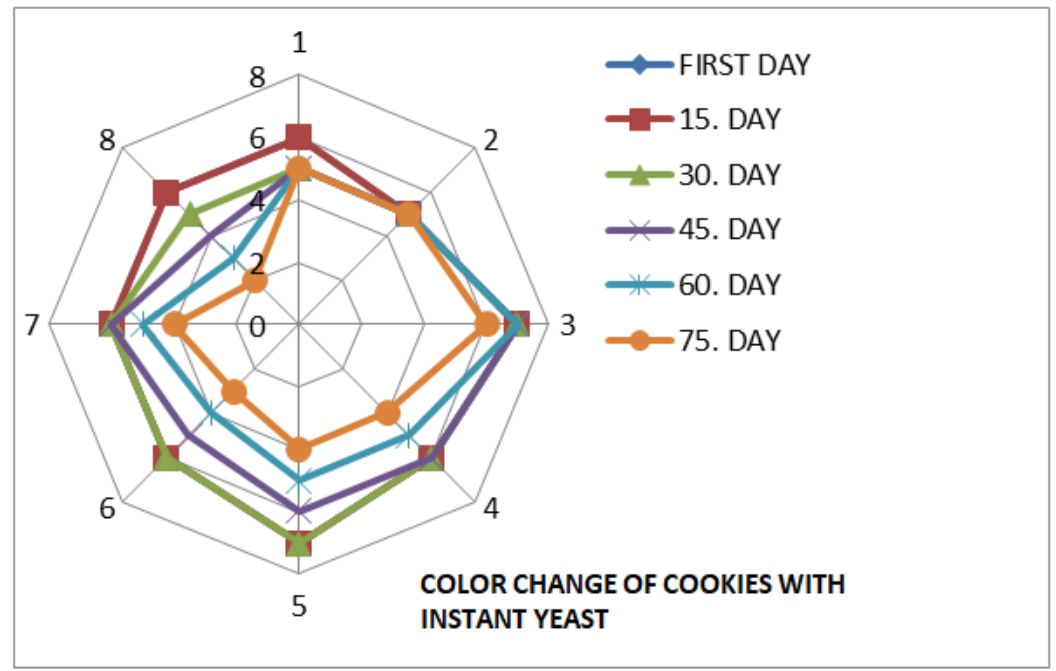

(d)

Figure 11 Taste, odor and hardness change of cookies with instant yeast with time.

When the results were examined, the quality reduction of the taste, smell and hardness of the cookies made with instant yeast started in 45 days. The shelf life of the cookies made with instant yeast can be called 45 at room temperature, while the shelf life of cookies with chickpea yeast can be called as 2.5 months. Because, when the results of the experiment were examined, the deterioration in the quality parameters of cookies made with instant yeast started in 45 days, whereas the deterioration in the quality parameters of cookies made with chickpea yeast started in 75 days and the experiment was concluded in 75 days. According to the experimental results, chickpea yeast prolongs the shelf life and also increases the quality parameters of Gaziantep village cookies. Chickpea yeast is a sweet fermented yeast and has a unique aroma and flavor. This flavor and aroma is reflected in the taste and other quality parameters of cookies. This is the main difference between commercial yeast and instant yeast.

\section{CONCLUSIONS AND RECOMMENDATIONS}

In this study, it was concluded that chickpea yeast prolongs the shelf life of Gaziantep village cookies at room temperature and increases the quality parameters of its. It is thought that this product, which lasts for 2.5 months without adding any additives or artificial preservatives, should be manufactured in the factory and take its place on the shelves of the market as packaged product. It is suitable for mass production and is also thought to be a good alternative for people who want to eat naturally and locally. The shelf life of cookies with chickpea yeast is 2.5 months at room temperature, which means that this

27 I P a g e 
International Journal of Scientific and Technological Research

ISSN 2422-8702 (Online), DOI: 10.7176/JSTR/6-10-03

Vol.6, No.10, 2020

product can be easily exported without requiring extra transportation conditions. Low transportation costs are an advantage to promote this local cookies.

\section{REFERENCES}

https://gastromanya.com/gaziantep-mutfagi-hakkinda-genel-bilgiler/

http://gaziantepface.com/koseyazisi/gaziantep-kahkeleri-yazisi-63.html 